\title{
CONF- $970834-2$
}

\section{QUANTIFICATION OF INTERFACIAL SEGREGATION ION MICROSCOPY}

\author{
M.K. Miller
}

Metals and Ceramics Division, Oak Ridge National Laboratory, Oak Ridge, TN 37831-6376

The atom probe field ion microscope is a powerful technique for the quantification of solute segregation at internal interfaces due to its ultrahigh spatial resolution. The segregation behavior for all elements is determined by collecting the atoms that originate in a cylinder centered on the boundary region. The method of analysis is dictated by the orientation of the boundary in the field ion specimen. The general case and the two special orientations are shown schematically in Fig. 1. The special case where the unit normal to the interface plane is at $90^{\circ}$ to the unit vector parallel to the cylinder of analysis, $\phi=90^{\circ}$, permits a large number of atoms to be collected but the spatial resolution is defined by the effective diameter of the probe aperture and is typically chosen to be between 1 to $5 \mathrm{~nm}$. The special case where $\phi=0^{\circ}$ provides the highest spatial resolution but only a limited number of atoms are collected from the boundary in each cylinder of analysis. In this special orientation and the general case, the number of atoms collected from the boundary and hence the statistics can be improved by making several passes through the boundary by moving the probe aperture after each crossing, as shown in Fig. 1. The solute coverage at the interface may be fundamentally determined from the atoms in this cylinder of analysis with a method based on the Gibbsian interfacial excess. The Gibbsian interfacial excess of element $\mathrm{i}$, is defined as $\Gamma_{\mathrm{i}}=\mathrm{N}_{\mathrm{i}(\text { excess })} / \mathrm{A}=\left(\mathrm{N}_{\mathrm{i}}-\mathrm{N}_{\mathrm{i}(\alpha)}-\mathrm{N}_{\mathrm{i}(\beta)}\right) / \mathrm{A}$, where $\mathrm{N}_{\mathrm{i}(\text { excess })}$ is the excess number of solute atoms associated with the interface, $\mathrm{N}_{\mathrm{i}}$ is total number of solute atoms in the volume analyzed, and $\mathrm{N}_{\mathrm{i}(\alpha)}$ and $\mathrm{N}_{\mathrm{i}(\beta)}$, are the number of solute atoms in the two adjoining regions $\alpha$ and $\beta$ either side of the dividing surface. The interfacial area over which the excess is determined is given by $A=\pi r_{a}^{2} / \cos \phi,\left(\phi \neq 90^{\circ}\right)$ where $r_{a}$ is the effective radius of the probe aperture. The angle $\phi$ is determined from either the projection of the interface in the field ion micrographs or the examination of the field ion specimen in the transmission electron microscope.

In boron-doped $\mathrm{NiAl}$, the field ion image provides a good indication of grain boundary segregation due to the brightly-imaging nature of the boron atoms. The distribution of these boron atoms indicates that the coverage varied along the grain boundary, ${ }^{1}$ Fig. 2 . " The boron coverage along the boundary may also be estimated from the cylinder of analysis, Table 1 . In this material, the boron coverage was found to vary by a factor of $\sim 7.5$ from 3.6 to $27.4 \%$ or $\Gamma_{\mathrm{i}}=6.2$ to $46.3 \times 10^{17}$ atoms $\mathrm{m}^{-2}$. Boron enrichment was observed in both $\mathrm{Ni}$-depleted and $\mathrm{Ni}$-enriched sections of the grain boundary. No strong correlation between the $\mathrm{Ni}: \mathrm{Al}$ ratio and the coverage was apparent in these data.

A field ion micrograph of a $\Sigma 3$ coincident site lattice grain boundary in NiAl containing 0.7 at. \% Mo is shown in Fig. $3 .^{2}$ Despite the relatively low coverages, Table 2 , significant enrichments of Mo, $\mathrm{N} / \mathrm{Si}, \mathrm{C}, \mathrm{B}$, and $\mathrm{Fe}$ are evident at the grain boundary. A $21 / 2 \mathrm{D}$ reconstruction of the solute distribution along this grain boundary, Fig. 4 , was created by taking the $\mathrm{z}$ coordinate of each solute atom as its position along the composition profile. The solutes were then assumed to be randomly distributed along the boundary plane to give the $x$ coordinate $(y=0)$. Since the diameter of the cylinder of analysis varied from 3.4 to $4.3 \mathrm{~nm}$ during this analysis, this randomization will only introduce a small one-dimensional uncertainty in the reconstruction. Although most of the solute was distributed uniformly along the grain boundary, there was some visual evidence of regions of higher than average local concentrations of $\mathrm{Fe}, \mathrm{Mo}, \mathrm{N}$ and $\mathrm{C}$. There was also some evidence of Mo-N enrichment. ${ }^{3}$

1. R. Jayaram and M.K. Miller, Acta Metall., 42 (1994) 1561.

2. M.K. Miller, I.M. Anderson and K.F. Russell, Appl. Surf. Sci., 94/95 (1996) 288.

3. This research was sponsored by the Division of Materials Sciences, U. S. Department of Energy, under contract DE-AC05-96OR22464 with Lockheed Martin Energy Research Corp. This research was conducted utilizing the Shared Research Equipment (SHaRE) User Program facilities at Oak Ridge National Laboratory.

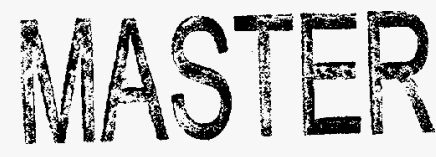

"The submitted manuscript has been authored by a contractor of the U.S. Government under contract DE-AC05-960R22464. Accordingly, the U.S.

DE-AC05-960R22464. Accordingly, the U.S.
Government retains a nonexclusive, royalty-free license

to publish or reproduce the published form of this

contribution, or allow others to do so, for U.S.

Government purposes."

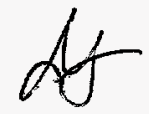


TABLE 1. The Gibbsian interfacial excesses of boron at a $\Sigma 3$ CSL grain boundary in NiAl +0.04 at. \% B aged $1 \mathrm{~h}$ at $900^{\circ} \mathrm{C}$.

\begin{tabular}{c|c|c|c}
\hline Analysis & $\mathrm{Ni}: \mathrm{Al}$ & $\Gamma_{\mathrm{i}}\left(\right.$ atoms $\left.\mathrm{m}^{-2}\right)$ & Coverage $(\%)$ \\
\hline 1 & 0.77 & $9.6 \times 10^{17}$ & 5.7 \\
2 & 0.91 & $6.2 \times 10^{17}$ & 3.6 \\
3 & 1.27 & $8.7 \times 10^{17}$ & 5.2 \\
4 & 0.79 & $8.7 \times 10^{17}$ & 5.2 \\
5 & 0.80 & $1.2 \times 10^{18}$ & 7.2 \\
6 & 0.88 & $1.3 \times 10^{18}$ & 7.6 \\
7 & 0.84 & $2.3 \times 10^{18}$ & 13.4 \\
8 & 0.94 & $1.5 \times 10^{18}$ & 9.1 \\
9 & 0.82 & $1.9 \times 10^{18}$ & 11.0 \\
10 & 0.81 & $4.6 \times 10^{18}$ & 27.4 \\
\hline
\end{tabular}

TABLE 2. The Gibbsian interfacial excesses of solute at a $\Sigma 3$ CSL grain boundary in $\mathrm{NiAl}+$ 0.7 at. $\%$ Mo aged $1 \mathrm{~h}$ at $1000^{\circ} \mathrm{C}+1 \mathrm{~h}$ at $500^{\circ} \mathrm{C}$.

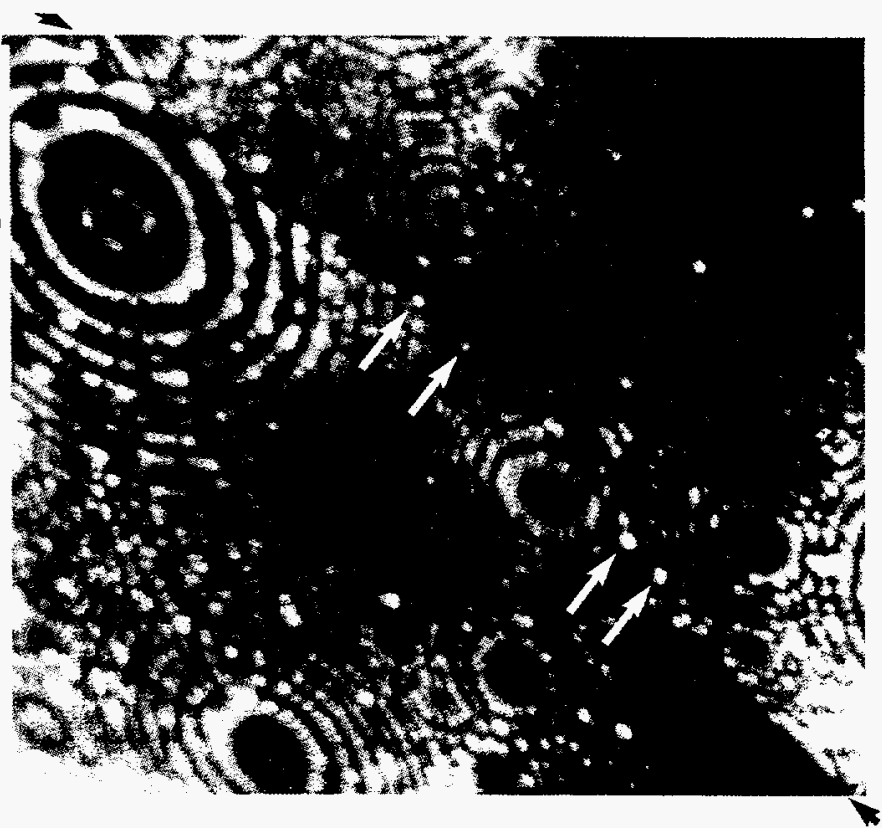

\begin{tabular}{c|c|c}
\hline Element & $\Gamma_{\mathrm{i}}$, atoms $\mathrm{m}^{-2}$ & Coverage, $\%$ \\
\hline $\mathrm{Mo}$ & $9.9 \times 10^{16}$ & 0.58 \\
$\mathrm{~N} / \mathrm{Si}$ & $6.5 \times 10^{16}$ & 0.38 \\
$\mathrm{C}$ & $1.1 \times 10^{16}$ & 0.07 \\
$\mathrm{~B}$ & $5.7 \times 10^{15}$ & 0.03 \\
$\mathrm{Fe}$ & $3.8 \times 10^{15}$ & 0.02 \\
\hline
\end{tabular}

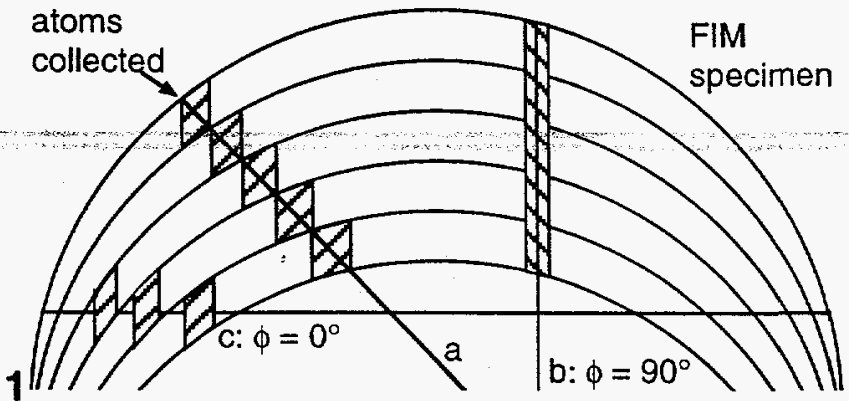

FiM

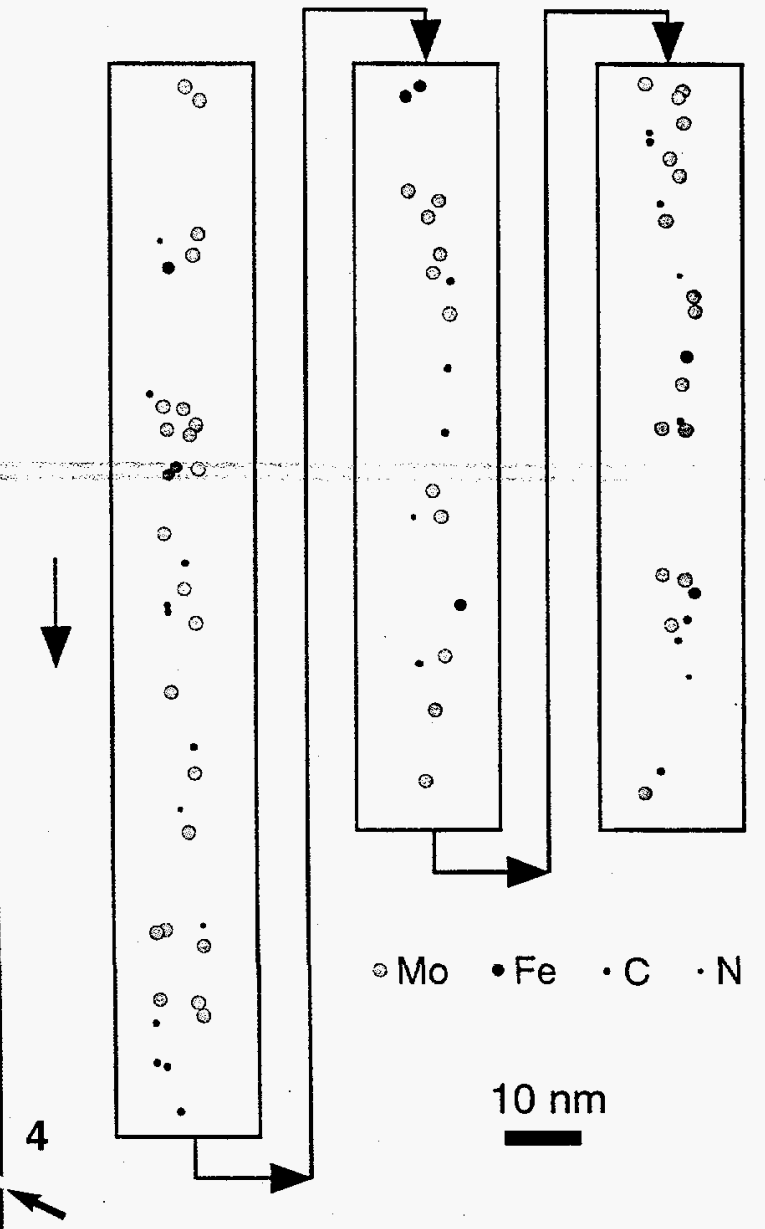

FIG. 1. Schematic diagram of the analysis of boundaries in the atom probe. Shaded region is the cylinder of analysis.

FIG. 2. Field ion micrographs of a boron-decorated grain boundary in NiAl. The brightly-imaging atoms are boron atoms.

FIG. 3. Field ion micrograph of a $\Sigma 3$ grain boundary in $\mathrm{NiAl}+0.7$ at. $\% \mathrm{~B}\left(\phi=90^{\circ}\right)$.

FIG. 4. $21 / 2 \mathrm{D}$ reconstruction of the distribution of $\mathrm{Mo}, \mathrm{Fe}, \mathrm{C}$ and $\mathrm{N}$ atoms at the grain boundary shown in Fig. 3 . 


\section{DISCLAIMER}

This report was prepared as an account of work sponsored by an agency of the United States Government. Neither the United States Government nor any agency thereof, nor any of their employees, makes any warranty, express or implied, or assumes any legal liability or responsibility for the accuracy, completeness, or usefulness of any information, apparatus, product, or process disclosed, or represents that its use would not infringe privately owned rights. Reference herein to any specific commercial product, process, or service by trade name, trademark, manufacturer, or otherwise does not necessarily constitute or imply its endorsement, recommendation, or favoring by the United States Government or any agency thereof. The views and opinions of authors expressed herein do not necessarily state or reflect those of the United States Government or any agency thereof. 



\section{DISCLAMMER}

Portions of this document may be illegible in electronic image products. Images are produced from the best available original docoment. 
